\title{
Salmonella Minnesota de origem avícola apresenta fatores de virulência e risco potencial aos humanos
}

\author{
[Salmonella Minnesota poultry origin has virulence factors and \\ potential risk to human] \\ R.T. Melo ${ }^{1}$, A.R. Resende ${ }^{2}$, E.P. Mendonça ${ }^{3}$, P.C. Nalevaiko ${ }^{2}$, \\ G.P. Monteiro ${ }^{2}$, A.B.G. Buiatte ${ }^{2}$, D.A. Rossi ${ }^{1}$ \\ ${ }^{1}$ Universidade Federal de Uberlândia - Uberlândia, MG \\ ${ }^{2}$ Aluno de pós-graduação - Universidade Federal de Uberlândia - Uberlândia, MG \\ ${ }^{3}$ Universidade de Uberaba - Uberaba, MG
}

\section{RESUMO}

Objetivou-se avaliar características de virulência, perfil de resistência antimicrobiana e padrão de similaridade genética de 71 cepas de Salmonella Minnesota isoladas na cadeia produtiva de frangos de corte, entre 2009 e 2010, em duas unidades de uma empresa (A e B). Os isolados foram sorotipificados e submetidos ao teste de susceptibilidade antimicrobiana pelo teste de difusão em disco. Utilizando-se PCR, foi avaliada a presença dos genes invA, lpfA, agfA e sefA e os genes de resistência aos betalactâmicos $\left(\right.$ bla $_{T E M}, b a_{S H V}$ e $\left.b l a_{C T X-M}\right)$. A relação filogenética foi determinada por RAPD-PCR. Os maiores percentuais de resistência foram para tetraciclina e sulfonamida. Foram reconhecidos oito perfis de resistência aos antimicrobianos entre as cepas isoladas na indústria $\mathrm{A}$, e 11 perfis de resistência na indústria B. Do total de cepas, $100 \%$ foram positivas para o gene invA, 98,6\% para o gene agfA, 49,3\% para o gene $l p f A$ e nenhuma para o gene sefA. Três cepas foram positivas para o gene bla $(15,5 \%)$ para o gene bla $a_{C T X-M}$. A avaliação filogenética demonstrou a presença de sete clusters com similaridade superior a $80 \%$ e três perfis distintos. Com base no dendrograma, observou-se a disseminação de um mesmo perfil em ambas as empresas.

Palavras-chave: fatores de patogenicidade, resistência antimicrobiana, salmonelose

\begin{abstract}
The aim of this study was to evaluate virulence characteristics, antimicrobial resistance profile and the pattern of genetic similarity of 71 strains of Salmonella Minnesota isolated in the production chain of broilers between 2009 and 2010, into two units of a company ( $A$ and B). Isolates were serotyped and submitted to antimicrobial susceptibility by disk diffusion test. Using PCR, the presence of genes invA, IpfA, agfA and sefA and the genes conferring resistance to beta-lactam (bla relationship was determined by the RAPD-PCR method. The highest percentages of resistance were to tetracycline and sulfonamide. Eight antimicrobial resistance profiles were recognized among strains isolated in industry A, and 11 resistance profiles in industry B. Of all strains of both industries, $100 \%$ were positive for the invA gene, $98.6 \%$ to agfA gene, 49.3\% for lpfA gene, and no strain showed the sefA gene. Three strains

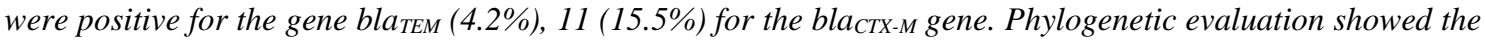
presence of seven clusters with similarity greater than $80 \%$ and three distinct profiles. Based on the dendrogram we observed the spread with similar profiles in both companies.
\end{abstract}

Keywords: pathogenicity factors, antimicrobial resistance, salmonellosis

\section{INTRODUÇÃO}

A salmonelose é uma das zoonoses mais complexas que afetam a saúde pública mundial. O patógeno tem alto poder de disseminação e é encontrado em uma ampla variedade de reservatórios animais. O consumo da carne de frango é considerado um importante fator de risco para ocorrência da doença em humanos (The European..., 2017). Vários sorotipos são

Recebido em 19 de junho de 2018

Aceito em 03 de julho de 2019

E-mail: roberta-melo@hotmail.com 
capazes de colonizar o trato intestinal de frangos de corte e contaminar as carcaças durante o abate e o processamento, o que representa um desafio extra para minimizar os riscos para os consumidores finais (Voss-Rech et al., 2015).

Outro aspecto importante é a dispersão de cepas resistentes aos antimicrobianos. O uso desses agentes nas medicinas humana e veterinária promove pressão seletiva, favorecendo o surgimento de cepas resistentes e estreitando a escolha de medicamentos terapeuticamente eficazes (Lai et al., 2014), o que leva a problemas como morbidade, mortalidade e os custos associados com a doença (Muhammad et al., 2010).

Recentemente, métodos de tipagem molecular de Salmonella vêm sendo utilizados para determinar a relação filogenética entre as cepas. A técnica de RAPD-PCR vem garantindo alto poder discriminatório e é amplamente utilizada em estudos epidemiológicos (Turki et al., 2014). No Brasil, há poucos trabalhos publicados sobre sorotipos de Salmonella não tifoide, já que o maior foco é aplicado aos sorovares Enteritidis e Typhimurium devido a questões de saúde pública (Vaz et al., 2010). Ainda assim, Salmonella Minnesota tem sido relacionada a surtos de salmonelose humana no mundo (Scientific..., 2014).

Considerando-se o aumento no número de isolamentos de Salmonella Minnesota em produtos avícolas, objetivou-se avaliar a resistência aos antimicrobianos e a presença de genes de virulência, assim como compreender o padrão de distribuição e disseminação desse sorovar no processo produtivo de frangos e os possíveis riscos que ele possa acarretar na saúde humana.

\section{MATERIAL E MÉTODOS}

O estudo foi realizado com 71 cepas de Salmonella Minnesota isoladas em duas unidades de abate de frangos de corte, com ciclos completos de produção e sistema de integração, localizadas nos estados de São Paulo (indústria A) e Mato Grosso do Sul (indústria B), Brasil, durante o período de 2009 a 2010. As plantas de abate possuíam serviço de inspeção federal e a carne de frango produzida era comercializada em todo o território nacional e exportada. As amostras foram coletadas em todo o ciclo de produção, desde granjas de frangos de corte até o produto final pronto para o comércio.

Foram analisadas 31 cepas provenientes dos aviários de frango de corte, isoladas a partir de amostras de suabes de arrasto do galpão (3) e de equipamentos (5) e suabes de cloaca (2), suabe de arrasto com propé (15) e propé (6), quando os frangos estavam com aproximadamente 30 dias. As 39 amostras provenientes do abatedouro foram coletadas nos pontos exigidos no Programa de Redução de Patógenos - PRP (Brasil, 2003) e, adicionalmente, em outros pontos que apresentavam maior frequência de isolamento de Salmonela na rotina das indústrias estudadas, incluindo amostras de cortes cárneos (17), carcaça inteira (16), miúdos (2), carne mecanicamente separada (2), água de escaldagem (1) e água de chiller (1). Também foi analisada uma amostra de suabe de caminhão da fábrica de ração. A tipificação antigênica foi realizada pela Fundação Instituto Oswaldo Cruz, no estado do Rio de Janeiro (Fiocruz).

A susceptibilidade das cepas aos antimicrobianos foi avaliada pela técnica de disco-difusão (Performance..., 2013). Os testes foram realizados no Laboratório de Biotecnologia Animal Aplicada da Universidade Federal de Uberlândia (Labio/UFU). O critério de escolha dos antimicrobianos baseou-se na utilização dessas drogas nas medicinas veterinária e humana e na ocorrência de resistência. Os antimicrobianos testados foram: amoxacilina $(10 \mu \mathrm{g})$, norfloxacino $(10 \mu \mathrm{g})$, neomicina $(30 \mu \mathrm{g})$, gentamicina $(10 \mu \mathrm{g})$, trimetropim $(5 \mu \mathrm{g})$, ceftazidima $(30 \mu \mathrm{g})$, cloranfenicol $(30 \mu \mathrm{g})$, imipenem $(10 \mu \mathrm{g})$, tetraciclina $(30 \mu \mathrm{g})$, sulfonamida $(300 \mu \mathrm{g})\left(\right.$ Laborclin $^{\circledR}$, Brasil). Foram pesquisados quatro genes de virulência em Salmonella Minnesota, relacionados com as fases de adesão, invasão e lesão em células intestinais (Tab. 1).

O DNA foi extraído por meio da utilização do kit Promega Wizard ${ }^{\circledR}$, seguindo recomendações do fabricante. A quantificação do DNA foi feita em espectrofotômetro (Femto 750 ${ }^{\circledR}$, Brasil) com comprimento de onda de 260nm. Para a realização das análises de PCR para a pesquisa dos genes de virulência, foi utilizada, como controle positivo, a cepa de Salmonella Enteritidis ATCC 13076. As reações de PCR 
foram realizadas a partir de um volume final de $25 \mu \mathrm{L}$, com $1 \mu \mathrm{L}$ de DNA da amostra, $2,5 \mu \mathrm{L}$ de tampão $10 \mathrm{X}, 0,75 \mu \mathrm{L}$ de $50 \mathrm{mM} \mathrm{MgCl}_{2}, 1,25 \mu \mathrm{L}$ de $10 \mathrm{pmol} / \mu \mathrm{L}$ da sequência forward e reverse de cada primer (Invitrogen ${ }^{\circledR}$, EUA), $0,25 \mu \mathrm{L}$ de $20 \mathrm{mM}$ do mix de DNTPs (Invitrogen ${ }^{\circledR}$, EUA), $0,25 \mu \mathrm{L}$ de Taq $(5 \mathrm{U} / \mu \mathrm{L})$ (Invitrogen ${ }^{\circledR}$, EUA) e $17,75 \mu \mathrm{L}$ de $\mathrm{H}_{2} \mathrm{O}$ ultrapura.

Tabela 1. Genes de virulência, sequência, tamanho de amplicon (pb) e referência bibliográfica

\begin{tabular}{|c|c|c|c|}
\hline Gene & Primers & Peso molecular & Referência \\
\hline invA & $\begin{array}{c}\text { F:5'GTGAAATTATCGCCACGTTCGGGCAA3' } \\
\text { R:5'TCATCGCACCGTCAAAGGAACC3' }\end{array}$ & $284 \mathrm{pb}$ & Oliveira et al. (2003) \\
\hline sefA & $\begin{array}{c}\text { F:5'GATACTGCTGAACGTAGAAGG3' } \\
\text { R:5'GCGTAAATCAGGATCTGCAGTAGC3', }\end{array}$ & $488 \mathrm{pb}$ & Oliveira et al. (2003) \\
\hline$a g f A$ & $\begin{array}{l}\text { F:5'TCCACAATGGGGCGGCGGCG3' } \\
\text { R:5'CCTGACGCACCATTACGCTG3' }\end{array}$ & $350 \mathrm{pb}$ & $\begin{array}{l}\text { Collinson et al. } \\
\quad \text { (1993) }\end{array}$ \\
\hline lpfA & $\begin{array}{l}\text { F:5'CTTTCGCTGCTGAATCTGGT3' } \\
\text { R:5'CAGTGTTAACAGAAACCAGT3', }\end{array}$ & $250 \mathrm{pb}$ & $\begin{array}{l}\text { Heuzenroeder } \text { et al. } \\
\text { (2000) }\end{array}$ \\
\hline
\end{tabular}

pb: pares de bases.

As amostras foram submetidas aos ciclos de temperatura em termociclador Eppendorf $^{\circledR}$, Alemanha), sendo desnaturadas a $94^{\circ} \mathrm{C}$ por cinco minutos, amplificadas em 35 ciclos de desnaturação a $94^{\circ} \mathrm{C}$ por 45 segundos, anelamento a $58^{\circ} \mathrm{C}$ por 30 segundos (invA); $50^{\circ} \mathrm{C}$ por 30 segundos (sefA e $\left.\operatorname{lpf} \mathrm{A}\right), 66^{\circ} \mathrm{C}$ por 30 segundos (agfA); extensão a $72^{\circ} \mathrm{C}$ por 90 segundos, com extensão final a $72{ }^{\circ} \mathrm{C}$ por 10 minutos. Cada gene foi avaliado separadamente.
As cepas também foram avaliadas quanto à presença de genes de resistência aos antibióticos do grupo dos $\beta$-lactâmicos. Para a realização das análises de PCR, foi utilizada, como controle positivo, uma cepa de campo de Klebsiella pneumoniae, previamente testada para a presença dos três genes estudados. O preparo do mix para as reações de PCR foi o mesmo descrito para os genes de virulência. Os genes estudados foram avaliados separadamente e estão descritos na Tab. 2.

Tabela 2. Genes de resistência, sequência, peso molecular (pb) e referência bibliográfica

\begin{tabular}{|c|c|c|c|}
\hline Gene & Primers & $\begin{array}{c}\text { Peso } \\
\text { molecular }\end{array}$ & Referência \\
\hline$b l a_{\mathrm{TEM}}$ & $\begin{array}{l}\text { F: 5'CAGCGGTAAGATCCTTGAGA3' } \\
\text { R: 5'ACTCCCCGTCGTGTAGATAA3' }\end{array}$ & $643 \mathrm{pb}$ & $\begin{array}{l}\text { Chen et al. } \\
\quad(2004)\end{array}$ \\
\hline$b l a_{\mathrm{SHV}}$ & $\begin{array}{l}\text { F: 5'GGCCGCGTAGGCATGATAGA3' } \\
\text { R: 5'CCCGGCGATTTGCTGATTTC3' }\end{array}$ & $714 \mathrm{pb}$ & $\begin{array}{l}\text { Chen et al. } \\
\quad \text { (2004) }\end{array}$ \\
\hline$b l a_{\mathrm{CTX}-\mathrm{M}}$ & $\begin{array}{c}\text { F: 5'ATGTGCAGYACCAGTAARGTKATGGC3' } \\
\text { R: 5'TGGGTRAARTARGTSACCAGAAYCAGCGG3' }\end{array}$ & $593 \mathrm{pb}$ & $\begin{array}{l}\text { Monstein } e t \\
\text { al., (2007) }\end{array}$ \\
\hline
\end{tabular}

As condições de amplificação foram as seguintes: desnaturação inicial a $94^{\circ} \mathrm{C}$ por cinco minutos, 30 ciclos de desnaturação a $94^{\circ} \mathrm{C}$ por 45 segundos, anelamento a $50^{\circ} \mathrm{C}$ por 45 segundos (bla $\left.a_{\mathrm{TEM}}\right), 56^{\circ} \mathrm{C}$ por 45 segundos (bla $\left.a_{\mathrm{SHV}}\right)$ e $58^{\circ} \mathrm{C}$

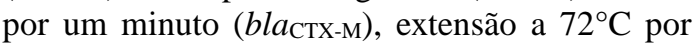
90 segundos, seguida de uma extensão final de $72^{\circ} \mathrm{C}$ por 10 minutos.

Os isolados foram submetidos à análise gênica por RAPD (Random Amplified Polymorphic $D N A$ ), utilizando-se o protocolo descrito por
Oliveira et al. (2007). As reações de RAPD-PCR foram realizadas com dois iniciadores, individualmente, os quais foram descritos por Lin et al. (1996): 23L (5' - CCGAAGCTGC - 3') e P1254 (5' - CCGCAGCCAA - 3'). Como controle positivo, foi utilizada a cepa ATCC 13076 de Salmonella Enteritidis.

A técnica de RAPD-PCR foi realizada a partir de um volume final de $25 \mu \mathrm{L}$ contendo $1 \mu \mathrm{L}$ de DNA da amostra a $50 \mathrm{ng}, 2,5 \mu \mathrm{L}$ de tampão $10 \mathrm{X}$, $0,75 \mu \mathrm{L}$ de $50 \mathrm{mM} \mathrm{MgCl}_{2}, 1,25 \mu \mathrm{L}$ de $10 \mathrm{pmol} / \mu \mathrm{L}$ 
da sequência forward e reverse de cada primer (Invitrogen $^{\circledR}$ ), $0,25 \mu \mathrm{L}$ de $20 \mathrm{mM}$ do mix de DNTPs (Invitrogen ${ }^{\circledR}$, EUA), $0,25 \mu \mathrm{L}$ de Taq $(5 \mathrm{U} / \mu \mathrm{L})$ (Invitrogen ${ }^{\circledR}$, EUA) e $17,75 \mu \mathrm{L}$ de $\mathrm{H}_{2} \mathrm{O}$ ultrapura. A concentração utilizada para os iniciadores foi de 50pmol para P1254 e de 30 pmol para $23 \mathrm{~L}$. A reação PCR foi conduzida dentro das seguintes condições: um ciclo de $94^{\circ} \mathrm{C}$ por quatro minutos, seguido de 35 ciclos de $94^{\circ} \mathrm{C}$ por um minuto, $35^{\circ} \mathrm{C}$ por um minuto, $72^{\circ} \mathrm{C}$ por dois minutos, e extensão final de $72^{\circ} \mathrm{C}$ por cinco minutos.

Todas as reações de PCR foram realizadas no termociclador (Eppendorf $^{\circledR}$, Alemanha); os produtos amplificados foram separados por eletroforese em gel de agarose a $1,5 \%$ por 120 minutos. O gel foi corado com Syber Safe (Invitrogen ${ }^{\circledR}, \quad$ EUA) e visualizado em transluminador UV (Loccus Biotecnologia, Brasil).

Os resultados obtidos foram tabulados $\mathrm{e}$ submetidos à análise por meio da estatística descritiva, com cálculo das porcentagens de resistência antimicrobiana e de presença de genes de virulência nos isolados de Salmonella Minnesota. Para a análise de similaridade genética entre as cepas, utilizou-se análise computacional pelo Programa GelCompar II. A análise final foi baseada na média de experimentos (average from experiments) pelo método UPGMA (Unweighted pair group method with arighmetic mean) para construção do dendrograma.

\section{RESULTADOS E DISCUSSÃO}

A Fig. 1 demonstra os percentuais de resistência obtidos para os 10 antimicrobianos avaliados nos isolados de Salmonella Minnesota das duas unidades industriais. Os percentuais demonstrados referem-se à somatória dos isolados classificados como resistentes e intermediários pelo teste de disco-difusão. Podese observar que houve maior índice de resistência nas duas indústrias para tetraciclina e sulfonamida, com $93,8 \%$ na indústria $\mathrm{A}$, e $89,7 \%$ na indústria $\mathrm{B}$, os quais tiveram seu uso banido no Brasil como promotores de crescimento (Brasil, 2009). Todas as cepas caracterizadas foram sensíveis ao norfloxacina e ao imipenem.

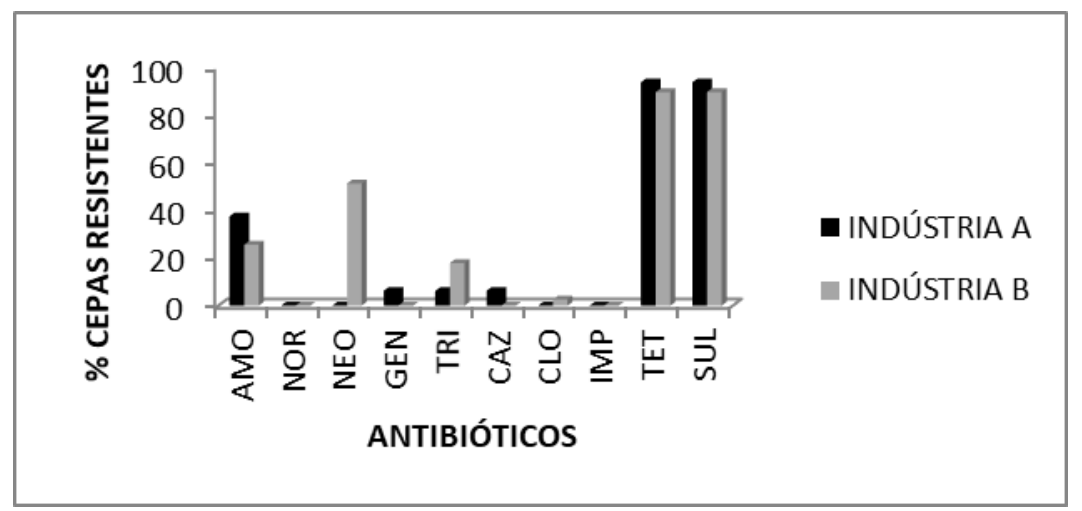

AMO: amoxacilina $(10 \mu \mathrm{g})$; NOR: norfloxacino $(10 \mu \mathrm{g})$; NEO: neomicina $(30 \mu \mathrm{g})$; GEN: gentamicina $(10 \mu \mathrm{g})$; TRI: trimetoprima $(5 \mu \mathrm{g})$; CAZ: ceftazidima $(30 \mu \mathrm{g})$; CLO: cloranfenicol $(30 \mu \mathrm{g})$; IMP: imipenem $(10 \mu \mathrm{g})$; TET: tetraciclina $(30 \mu \mathrm{g})$; SUL: sulfonamida $(300 \mu \mathrm{g})$.

Figura 1. Percentual de resistência aos antimicrobianos em cepas de Salmonella Minnesota isoladas em duas indústrias com ciclo completo de produção de frangos de corte (Unidade A e Unidade B).

No Brasil, níveis de resistência antimicrobiana identificados em Salmonella spp. isolada de frango variam entre $56 \%$ e $100 \%$ (Cardoso et al., 2006; Vaz et al., 2010). O elevado percentual de resistência à tetraciclina era esperado, pois esse antimicrobiano é de primeira escolha na terapêutica para produção de frangos de corte
(Muhammad et al., 2010). Altos níveis de resistência à tetraciclina foram observados em Salmonella spp. isolada de carne de frango amostrado em plantas de processamento no Brasil, variando de $80 \%$ (Ribeiro et al., 2007) a 100\% (Sereno et al., 2017). 
O elevado percentual de isolados resistentes à sulfonamida observado neste estudo $(93,8 \%$ na indústria $\mathrm{A}$ e $89,7 \%$ na indústria $\mathrm{B}$ ) também foi verificado no Brasil, em carcaças de frango congeladas, provenientes de 15 cidades brasileiras, entre os anos de 2004 e 2006, e demonstrou $72,4 \%$ de cepas resistentes (Medeiros et al., 2011). As cefalosporinas e fluoroquinolonas são utilizadas para tratar infecções humanas graves (Lai et al., 2014). No presente estudo, 6,2\% das cepas na indústria $\mathrm{A}$ apresentaram resistência à ceftazidima; por outro lado, todas as estirpes foram sensíveis ao norfloxacino.

Houve diferenças nos percentuais de resistência entre as duas empresas, principalmente para neomicina, com $51,3 \%$ de cepas resistentes na indústria $\mathrm{B}$ e nenhuma resistente na indústria $\mathrm{A}$.
Diferentes fatores, como custo, disponibilidade e opção do médico veterinário, podem ter influenciado nos fenótipos de suscetibilidade ou resistência dessas populações. A administração cuidadosa de antimicrobianos e a vigilância contínua são iniciativas que ajudam a definir o melhor tratamento e dificultam a seleção e propagação de cepas resistentes (Voss-Rech et al., 2015).

Nas Tab. 3 e 4, estão apresentados os perfis de resistência de Salmonella Minnesota nas indústrias $\mathrm{A}$ e $\mathrm{B}$, respectivamente. Foram considerados multirresistentes os isolados que apresentaram resistência a três ou mais classes de antimicrobianos (Brasil, 2008). Das cepas avaliadas na indústria A (Tab. 3), 93,8\% apresentaram resistência a dois ou mais agentes antimicrobianos estudados.

Tabela 3. Perfis de resistência de 32 cepas de Salmonella Minnesota isoladas em uma cadeia de produção avícola localizada no estado de São Paulo (indústria A)

\begin{tabular}{cccc}
\hline Perfis & Resistência antimicrobiana* & Número de classes & Número de cepas $(\%)$ \\
\hline A1 & SUL TET & 2 & $16(50,0)$ \\
A2 & SUL TET (AMO) & 3 & $1(3,1)$ \\
A3 & SUL TET GEN & 3 & $2(6,2)$ \\
A4 & SUL TET AMO & 3 & $7(21,9)$ \\
A5 & SUL TET AMO (CAZ) & 3 & $1(3,1)$ \\
A6 & SUL TET TRI (AMO) & 4 & $2(6,2)$ \\
A7 & SUL TET AMO CAZ & 3 & $1(3,1)$ \\
A8 & Multissensíveis & - & $2(6,2)$ \\
& Total & & $32(100,0)$ \\
\hline
\end{tabular}

*Perfis entre parênteses: cepas com resistência intermediária aos antimicrobianos. AMO: amoxacilina; GEN: gentamicina; TRI: trimetoprima; CAZ: ceftazidima; TET: tetraciclina; SUL: sulfonamida.

${ }^{1}$ Número de classes de antimicrobianos aos quais os isolados apresentaram resistência.

Foram reconhecidos oito perfis de resistência aos antimicrobianos (A1 a A8) entre as cepas isoladas na indústria $\mathrm{A}$ (Tab. 3), sendo os perfis mais frequentes o A1, que agrupava isolados resistentes à sulfonamida e à tetracilina $(50,0 \%)$, e o A4, com resistência associada à sulfonamida, à tetraciclina e à amoxacilina (21,9\%). Trinta $(93,8 \%)$ isolados de Salmonella Minnesota na indústria A apresentaram resistência ou resistência intermediária a pelo menos um antibiótico. Desses, $16(53,3 \%)$ foram resistentes a dois antimicrobianos (A1) e 14 (46,7\%) foram considerados multirresistentes, pois apresentaram resistência a três ou mais classes de antibióticos (A2 a A7). Apenas duas cepas foram sensíveis a todos os antibióticos testados.
Entre as 39 cepas de Salmonella Minnesota analisadas na indústria $\mathrm{B}, 11$ perfis foram identificados (B1 a B11), sendo os perfis B1, de cepas resistentes à sulfonamida e à tetraciclina, $\mathrm{e}$ B2, de cepas resistentes à sulfonamida, à tetraciclina e à neomicina, os mais frequentes, com 25,6\% cada. Com exceção do perfil B11, cujas cepas foram sensíveis a todos os antimicrobianos testados $(4 / 39-10,3 \%)$, os demais perfis agruparam $35(89,7 \%)$ cepas resistentes ou com resistência intermediária a pelo menos uma droga. Entre essas 35 cepas, 10 $(28,6 \%)$ foram resistentes a dois antibióticos (B1), e $25 \quad(71,4 \%)$ foram consideradas multirresistentes (B2 a B10), com destaque para uma cepa que apresentou resistência a seis classes de antibióticos (B10). Esta cepa foi 
isolada de carne mecanicamente separada na indústria $\mathrm{B}$.

Acredita-se que o uso incorreto ou ilegal de antimicrobianos na avicultura industrial acabou por selecionar cepas do sorovar Minnesota de caráter multirresistente, que acabaram se disseminando no ambiente. Associado a essa hipótese, pode ter ocorrido a disseminação de genes de resistência aos antimicrobianos. Quanto aos genes de resistência estudados, apenas três cepas apresentaram o gene bla $a_{\mathrm{TEM}}(4,2 \%)$, e 11 $(15,5 \%)$ o gene bla $a_{\text {CTX-M, não havendo }}$ positividade para o gene bla $a_{\mathrm{SHV}}$, todos relacionados à resistência aos antibióticos da classe dos $\beta$-lactâmicos.

Tabela 4. Perfis de resistência de 39 cepas de Salmonella Minnesota isoladas em uma cadeia de produção avícola localizada no estado de Mato Grosso do Sul (indústria B)

\begin{tabular}{llll}
\hline Perfis & Resistência antimicrobiana* & Número de classes $^{1}$ & Número de cepas $(\%)$ \\
\hline B1 & SUL TET & 2 & $10(25,6)$ \\
B2 & SUL TET (NEO) & 3 & $10(25,6)$ \\
B3 & SUL TET (AMO) & 3 & $1(2,6)$ \\
B4 & SUL TET (AMO) (NEO) & 4 & $2(5,1)$ \\
B5 & SUL TET TRI & 3 & $2(5,1)$ \\
B6 & SUL TET TRI (NEO) & 4 & $3(7,6)$ \\
B7 & SUL TET TRI (AMO) & 4 & $1(2,6)$ \\
B8 & SUL TET AMO & 3 & $1(2,6)$ \\
B9 & SUL TET AMO (NEO) & 4 & $4(10,3)$ \\
B10 & SUL TET TRI CLO (AMO) (NEO) & 6 & $1(2,6)$ \\
B11 & Multissensíveis & - & $4(10,3)$ \\
& Total & & $39(100,0)$ \\
\hline
\end{tabular}

*Perfis entre parênteses: cepas com resistência intermediária aos antimicrobianos. AMO: amoxacilina; NEO: neomicina; TRI: trimetoprima; CLO: cloranfenicol; TET: tetraciclina; SUL: sulfonamida.

${ }^{1}$ Número de classes de antimicrobianos aos quais os isolados apresentaram resistência.

O percentual de resistência observado nas indústrias $\mathrm{A}$ e $\mathrm{B}$ foi considerado baixo para a cefalosporina ceftazidima $(2,8 \%)$ e para os carbapenêmicos (imipenem - 0\%). Já para os $\beta$ lactâmicos, do grupo das penicilinas (amoxacilina), houve um percentual de $31 \%$ de cepas resistentes. Desde 2000, na medicina humana, enzimas CTX-M são as mais relevantes, tanto em nível hospitalar quanto na comunidade, para identificar resistência tipo ESBL, suplantando as enzimas pertencentes às famílias TEM e SHV (Bonnet, 2004).

Neste estudo, 10 cepas de Salmonella apresentaram característica de resistência ou resistência intermediária, pelo teste de discodifusão, apenas ao $\beta$-lactâmico amoxacilina, e duas foram resistentes à amoxacilina e também à ceftazidima. Embora fenotipicamente tenham apresentado resistência aos $\beta$-lactâmicos, esses isolados não apresentaram a presença de nenhum dos genes avaliados, indicando que a resistência pode estar associada à presença de outras $\beta$ lactamases, que não foram avaliadas neste estudo, e/ou de outros mecanismos de resistência aos antibióticos $\beta$-lactâmicos.
Verificou-se que, do total das cepas de Salmonella Minnesota isoladas nas duas indústrias, $100 \%$ foram positivas para o gene invA e nenhuma apresentou o gene sefA. O gene agfA foi identificado em 98,6\% (70/71) das cepas, e o lpfA em 49,3\% (35/71). Houve 52,1\% de positividade para dois genes concomitantemente, e 47,9\% para três dos genes avaliados. A positividade para o gene invA para todas as cepas era esperada e concorda com estudo anterior (Rowlands et al., 2014). A presença desse gene é fundamental na expressão da capacidade de invasão dos tecidos do hospedeiro (Amini et al., 2010). A ausência do gene sefA é condizente com a literatura, uma vez que a fímbria SefA não está presente em todos os sorovares, sendo restrita ao grupo D das Salmonellas, nos sorotipos Enteritidis, Dublin, Moscow e Blegdon (Amini et al., 2010).

A identificação comum dos genes invA, lpfA e agfA em 47,9\% (34/71) das cepas indica que, além da capacidade de invasão, essas cepas também são eficientes no processo de adesão e na formação de biofilmes. Assim, seu isolamento em amostras ambientais, de carcaças e de miúdos 
pode indicar uma fonte de contaminação persistente nas unidades de produção. Borges et al. (2013) também observaram esse padrão em Salmonellas provenientes do Brasil. Além disso, a presença dessas fímbrias (genes agfA e lpfA) é de extrema importância no processo de infecção. É possível que haja efeitos aditivos das adesinas Lpf e Agf na colonização do intestino e expressão de virulência no hospedeiro, que indicam potencial risco após infecção.
A análise de similaridade de Salmonella Minnesota pelo dendrograma demonstrou elevada proximidade genética entre as cepas (Fig. 2). Não foram detectados clones com $100 \%$ de homologia. Porém o estudo permitiu identificar os genótipos distintos e clusters com homologia superior a $80 \%$, que foram comparados considerando-se o local de isolamento, a data da coleta, o perfil de resistência antimicrobiana e a presença dos genes invA, lpfA e agfA.

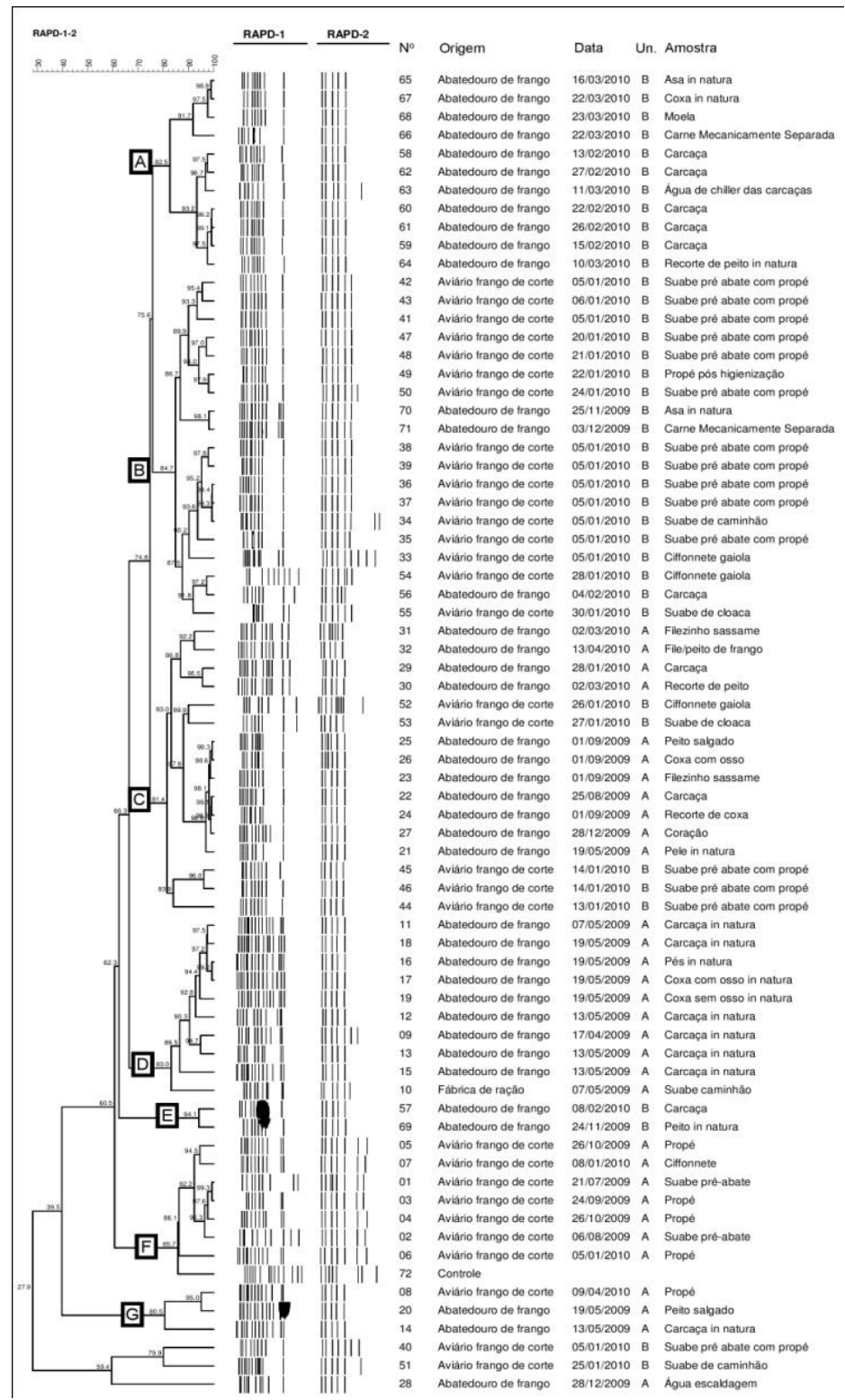

Figura 2. Dendrograma comparativo de $S$. Minnesota utilizando coeficiente de similaridade de Dice com tolerância de $1,5 \%$ e método UPGMA com otimização de $0,80 \%$. Perfis A a $\mathrm{G}$ - diferentes grupos clonais, com homologia superior a $80 \%$. 
Foram identificados sete clusters e três isolados que apresentaram perfil distinto, de forma que não puderam ser agrupados com as demais cepas pelo fato de a proximidade genética ser inferior a $80 \%$. O cluster A agrupou 11 cepas com homologia de $82,5 \%$, todas oriundas do abatedouro de frangos da unidade B. Esse perfil esteve presente por um período de dois meses nas amostras de alimentos e em uma amostra de água de chiller das carcaças. A água de chiller é considerada um fator importante na disseminação de Salmonella no abatedouro, já que um grande número de carcaças passa no mesmo tanque de água, o que aumenta as chances de contaminação cruzada (Mead et al., 2000).

A presença dos genes lpfA e agfA em $72,7 \%$ dessas cepas (8/11) mostra que elas possuem potencial para produzir biofilmes, caso haja expressão das características genéticas identificadas. Isso, aliado à não detecção desse perfil no ambiente da granja, permite inferir que a contaminação do produto no abatedouro não está relacionada à infecção prévia dos animais e, sim, à contaminação no próprio abatedouro.

Foram agrupadas 19 cepas no cluster B com similaridade de $84,7 \%$, provenientes tanto do aviário quanto do abatedouro da unidade B. Esse genótipo foi identificado por quatro meses na empresa. O extenso período de permanência sugere que houve infecção em lotes sucessivos de animais, associada à manutenção do microorganismo no ambiente do aviário, e consequente contaminação do produto no abatedouro, o que indica que a contaminação cruzada parece ser importante na disseminação desse genótipo ao longo da cadeia de produção. Logo, a presença desse perfil em amostras de suabes de gaiola, do caminhão de transporte e do ambiente pré-abate sugere a negligência às normas de biosseguridade na unidade de produção.

A presença do gene agfA em todas as cepas do cluster B indica que provavelmente esse genótipo se mantém devido à formação de agregados de culturas sésseis. Também foram identificados dois perfis de resistência em comum nesse grupo, B1 e B2 (Tab. 4), presente em 14/19 $(73,7 \%)$ cepas. As superfícies da indústria de processamento de alimentos, quando apresentam formação de biofilmes, caracterizam importantes fontes de contaminação. Essas estruturas permitem o crescimento e a sobrevivência de Salmonella spp. em condições ambientais estressantes. Uma vez instalado, o biofilme torna-se uma fonte de contaminação constante. A aplicação de boas e eficientes práticas e higiene e desinfecção permite a prevenção de formação ou a remoção dessas estruturas (Reuter et al., 2010).

No cluster C, 16 cepas apresentaram similaridade equivalente a 81,4\%, estando presentes em ambas as empresas tanto no aviário quanto no abatedouro. Esse fato implica a provável disseminação desse perfil nas duas unidades de produção. A permanência desse genótipo variou, entre os meses de agosto de 2009 e abril de 2010, no abatedouro da unidade A. A persistência do agente pode ter relação com a presença do gene agfA detectado em todas as cepas. Porém, é provável que a alternância nos períodos em que o genótipo foi encontrado seja devido a algum processo de injúria, que reduziu sua presença em números não detectáveis na metodologia tradicional.

De maneira distinta, na unidade B, esse perfil se manteve somente por um mês no aviário e não foi detectado no ambiente do abatedouro ou no alimento, o que indica um controle mais eficiente, que impediu sua permanência naqueles ambientes. O cluster $\mathrm{D}$ apresentou proximidade genética de $83 \%$ entre as nove cepas oriundas do abatedouro e uma cepa da fábrica de ração da unidade A. Possivelmente a ração foi a fonte primária de infecção dos animais na granja que gerou a contaminação das amostras do abatedouro, uma vez que houve coincidência nos períodos em que esse genótipo foi detectado (maio de 2009). A presença dos genes invA, lpfA e agfA foi comum nesse grupo, além do perfil de resistência A1 (Tab. 3) encontrado em $60 \%$ (6/10) das cepas.

Salmonela spp. pode contaminar a ração, principalmente por meio de ingredientes contaminados e da sua capacidade de formar biofilmes (Milanov et al., 2017). A peletização reduz a contaminação, mas pode não eliminá-la completamente devido à possibilidade de recontaminação após o processamento térmico (Jones, 2011). Sete cepas do aviário da unidade A foram agrupadas no cluster $\mathrm{F}$, com homologia de $85,7 \%$. São cepas do ambiente da granja com persistência alternada entre os meses de julho de 2009 e janeiro de 2010, justificável pela provável formação de biofilmes, resultante da expressão 
dos genes lpfA e agfA identificados nesse genótipo. Devido ao baixo número de cepas agrupadas nos clusters E e G, respectivamente, não é possível realizar uma análise fidedigna dos dados encontrados.

\section{CONCLUSÃO}

Nas duas unidades produtivas avaliadas (A e B), $46,7 \%$ e $71,4 \%$ dos isolados de Salmonella Minnesota, respectivamente, apresentaram perfil de multirresistência. Todos os isolados foram sensíveis ao norfloxacino e ao imipenem. A ocorrência de resistência à amoxacilina não pôde ser correlacionada com a presença dos genes de resistência estudados, indicando que outros fatores de resistência podem estar envolvidos. $\mathrm{O}$ potencial patogênico das cepas observado pela presença dos genes de virulência indica a possibilidade do sorovar $S$. Minnesota em causar doença clínica em humanos. A análise filogenética demonstrou a persistência dos genótipos no ambiente e a consequente contaminação do alimento produzido. Esses resultados revelam a necessidade de vigilância contínua e estudos de caracterização genética das cepas como ferramenta auxiliar nas estratégias de controle de Salmonella em frangos de corte e, consequentemente, na saúde pública.

\section{REFERÊNCIAS}

AMINI, K.; SALEHI, T.Z.; NIKBAHKHT, G. et al. Molecular detection of $i n v A$ and $s p v$ virulence genes in Salmonella Enteritidis isolated from human and animals in Iran. Afr. J. Microbiol. Res., v.4, p.2202-2210, 2010.

BONNET, R. Growing group of Extendedspectrum $\beta$-Lactamases: the CTX-M enzymes. Antimicrobiol. Agents Chemother., v.48, p.1-14, 2004.

BORGES, K.A.; FURIAN, T.Q.; BORSOI, A. et al. Detection of virulence-associated genes in Salmonella Enteritidis isolates from chicken in Southern Brazil. Pesqui. Vet. Bras., v.33, p.14161422, 2013.

BRASIL. Ministério da Agricultura, Pecuária e Abastecimento. Instrução Normativa $\mathrm{N}^{\circ} 70$, de 06 de outubro de 2003. Institui o Programa de Redução de Patógenos - Monitoramento Microbiológico e Controle de Salmonella sp. em carcaças de frangos e perus. Diário Oficial da União, Brasília, DF, 10 out. 2003. Seção 1, p.9.
BRASIL. Ministério da Agricultura, Pecuária e Abastecimento. Instrução Normativa $\mathrm{N}^{\mathrm{o}} 26$, de 09 de julho de 2009. Aprova o regulamento técnico para a fabricação, o controle de qualidade, a comercialização e o emprego de produtos antimicrobianos de uso veterinário. Diário Oficial da União, Brasília, DF, 10 jul. 2009. Seção 1, p.14.

BRASIL. Ministério da Saúde. Agência Nacional de Vigilância Sanitária - Anvisa. Relatório do monitoramento da prevalência e do perfil de suscetibilidade aos antimicrobianos em enterococos e salmonelas isolados de carcaças de frango congeladas comercializadas no Brasil. Programa Nacional de Monitoramento da Prevalência e da Resistência Bacteriana em Frango (PREBAF). Brasília, 2008. 186p.

CARDOSO, M.; RIBEIRO, A.R.; SANTOS, L.R. et al. Antibiotic resistance in Salmonella Enteritidis isolated from broiler carcasses. Braz. J. Microbiol., v.37, p.299-302, 2006.

CHEN, S.; ZHAO, S.; WHITE, D.G. et al. Characterization of Multiple-AntimicrobialResistant Salmonella Serovars Isolated from Retail Meats. Appl. Environ. Microbiol., v.70, p.1-7, 2004.

COLLINSON, K.; DOIG, P.C.; DORAN, J.L. et al. Thin aggregative fimbriae mediate binding of Salmonella Enteritidis to fibronectin. J. Bacteriol., v.175, p.12-18, 1993.

HEUZENROEDER, M.W.; MURRAY, C.J.; DALCIN, R.M. Molecular basis of benign colonization of Salmonella Sofia in chickens. Kingston: Rural Ind. R\&D Corporation, 2000. v.1, 106p.

JONES, F.T. A review of practical Salmonella control measures in animal feed. J. Appl. Poult. Res., v.20, p.102-113, 2011.

LAI, J.; WU, C.O.; WU, C.H. Serotype distribution and antibiotic resistance of Salmonella in food-producing animals in Shandong province of China, 2009 and 2012. Int. J. Food Microbiol., v.180, p.30-38, 2014.

LIN, A.W.; USERA, A.M.; BARRET, T.J.; GOLDSBY, R.A. Application of random amplified polymorphic DNA analysis to differentiate strains of Salmonella Enteritidis. J. Clin. Microbiol., v.34, p.870-876, 1996. 
MEAD, G.C.; ALLEN, V.M.; BURTON, C.H.; CORRY, J.E.L. Microbial crosscontamination during air chilling of poultry. Br. Poult. Sci., v.41, p.158-162, 2000.

MEDEIROS, M.A.N.; OLIVEIRA, D.C.N.; RODRIGUES, D.P.; FREITAS, D.R.C. Prevalence and antimicrobial resistance of Salmonella in chicken carcasses at retail in 15 Brazilian cities. Rev. Panam. Salud Publica, v.30, p.555-560, 2011.

MILANOV, D.; LJUBOJEVIC, D.; CABARKAPA, I. et al. Biofilm as risk for Salmonella contamination in various stages of poultry production. Eur. Poult. Sci., v.81, 2017.

MONSTEIN, H.J.; ÖSTHOLM-BALKHED, Å.; NILSSON, N.V. et al. Multiplex PCR amplification assay for rapid detection of blaSHV, blaTEM and blaCTX-M genes in Enterobacteriaceae. APMIS, v.115, p.1400-1408, 2007.

MUHAMMAD, M.; MUHAMMAD, L.U.; AMBALI, A.G. et al. Prevalence of Salmonella associated with chick mortality at hatching and their susceptibility to antimicrobial agents. Vet. Microbiol., v.140, p.131-135, 2010.

OLIVEIRA, F.A.; FRAZZON, A.P.G.; BRANDELLI, A.; TONDO, E.C. Use of PCRribotyping, RAPD, and antimicrobial resistance for typing of Salmonella Enteritidis involved in food-borne outbreaks in Southern Brazil. $J$. Infect. Dev. Ctries, v.1, p.170-176, 2007.

OLIVEIRA, S.D.; RODENBUSCH, C.R.; MICHAEL, G.B. et al. Detection of virulence genes in Salmonella Enteritidis isolates from different sources. Braz. J. Microbiol., v.34, p.123-124, 2003.

PERFORMANCE standards for antimicrobial susceptibility testing: twenty-third informational supplement. CLSI M100-S23, Wayne: CLSI, 2013.

REUTER, M.; MALLET, A.; BRUCE, M.P.; VAN VLIET, A.H.M. Biofilm formation by Campylobacter jejuni is increased under aerobic conditions. Appl. Environ. Microbiol., v.76, p.2122-2128, 2010.
RIBEIRO, A.R.; KELLERMANN, A.; SANTOS, L.R. et al. Salmonella spp. in raw broiler parts: Occurrence, antimicrobial resistance profile and phage typing of the Salmonella Enteritidis isolates. Braz. J. Microbiol., v.38, p.296-299, 2007.

ROWLANDS, R.E.G.; RISTORI, C.A.; IKUNO, A.A. et al. Prevalence of drug resistance and virulence features in Salmonella spp. isolated from foods associated or not with salmonellosis in Brazil. Rev. Inst. Med. Trop., v.56, p.461-467, 2014.

SCIENTIFIC report of EFSA and ECDC: the European Union summary report on trends and sources of zoonoses, zoonotic agents and foodborne outbreaks in 2012. EFSA J., v.12, p.3547, 2014.

SERENO, M.J.; ZIECH, R.E.; DRUZIANI, J.T. et al. Antimicrobial susceptibility and biofilm production by Salmonella sp. strains isolated from frozen poultry carcasses. Rev. Bras. Ciênc. Avíc., v.19, p.103-108, 2017.

THE EUROPEAN Union summary report on trends and sources of zoonoses, zoonotic agents and food-borne outbreaks in 2016. EFSA J., v.15, p.5077, 228p., 2017.

TURKI, Y.; MEHRI, I.; FHOULA, I. et al. Comparison of five molecular subtyping methods for differentiation of Salmonella Kentucky isolates in Tunisia. World $J$. Microbiol. Biotechnol., v.30, p.87-98, 2014.

VAZ, C.S.L.; STRECK, A.F.; MICHAEL, G.B. et al. Antimicrobial resistance and subtyping of Salmonella entérica subspecies enterica serovar Enteritidis isolated from human outbreaks and poultry in southern Brazil. Poult. Sci., v.89, p.1530-1536, 2010.

VOSS-RECH, D.; VAZ, C.S.L.; ALVES, L. et al. A temporal study of Salmonella enterica serotypes from broiler farms in Brazil. Poult. Sci., v.94, p.433-441, 2015. 